\title{
Research Progress of Organic Modified Montmorillonite
}

\author{
You-li Feng, Cong Wang*, Ning Mao, Meng-tao Wang, Li-jing Yu, Zhen-qiang Wei
}

School of Resources and Environment, Henan Polytechnic University, Jiaozuo, China

\section{Email address:}

wangcongo710@163.com (Cong Wang)

${ }^{*}$ Corresponding author

\section{To cite this article:}

You-li Feng, Cong Wang, Ning Mao, Meng-tao Wang, Li-jing Yu, Zhen-qiang Wei. Research Progress of Organic Modified Montmorillonite. Advances in Materials. Vol. 6, No. 3, 2017, pp. 20-23. doi: 10.11648/j.am.20170603.11

Received: April 7, 2017; Accepted: April 19, 2017; Published: June 3, 2017

\begin{abstract}
Montmorillonite is a layered aluminosilicate mineral and is a natural nanostructured material. At present, montmorillonite is widely used in polymer composites. With cation exchange, water absorption, dispersion and other functions are widely used. However, the surface polarity of montmorillonite is large and the compatibility with the polymer is poor, so it needs to be modified to be better dispersed in the polymer matrix. In this paper, the methods of organic modified montmorillonite and the adsorption properties of modified montmorillonite are discussed.
\end{abstract}

Keywords: Montmorillonite, Modification Method, Cation Exchange, Adsorption Performance

\section{Montmorillonite Structure}

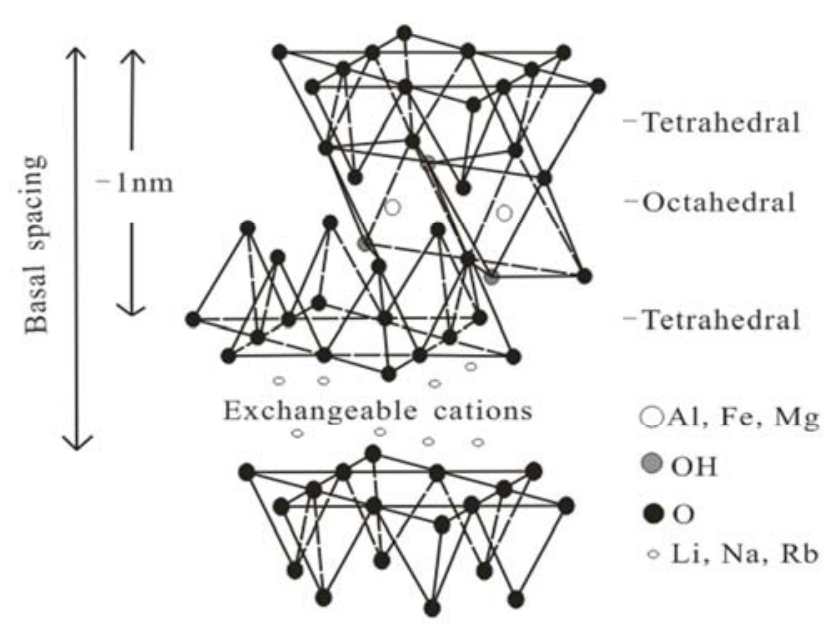

Figure 1. Schematic diagram of the structure of montmorillonite.

The main component of montmorillonite is a two-layer layered aluminosilicate of $2: 1$ type, and its unit cell is composed of two silicon oxide tetrahedrons with an aluminum oxide octahedron. The thickness of each layer is about $1 \mathrm{~nm}$, Interlayer adsorption is easy to be replaced by other cations $\mathrm{Ca}^{2+}, \mathrm{Mg}^{2+}, \mathrm{Na}^{+}$plasma [1]. This closely packed tetrahedron and octahedrons promote a highly ordered arrangement between the internal lattices (Figure 1). The tetrahedral and octahedrons are connected by the common oxygen atoms, and the unit cells are placed in parallel. $\mathrm{Si}^{4+}$ and $\mathrm{Al}^{3+}$ are easily replaced by other low-valent cations, such that the lamellae of the montmorillonite structure has a negative charge, and the excess negative charge depends on the adsorption of free ions between the layers of $\mathrm{Na}^{+}, \mathrm{Ca}^{2+}$ and $\mathrm{K}^{+}$and other cations to reach the unit cell charge balance.

\section{Montmorillonite Modification}

Montmorillonite has a good ion exchange, adsorption capacity, and affordable, storage capacity, pollution-free features, is widely used in chemical, petroleum, transportation, environmental protection, food, medicine, energy and other industries, known as for "omnipotent material". In order to meet the practical needs of all walks of life, especially heavy metal wastewater treatment, the need to improve the quality of montmorillonite and its efficiency, so montmorillonite to be modified. Montmorillonite modification method can be divided into three kinds of general: inorganic modification, organic modification and inorganic/organic compound modification, the most commonly used organic modification [4]. 
Table 1. Commonly used montmorillonite modification method.

\begin{tabular}{ll}
\hline Commonly used montmorillonite modification method \\
\hline Inorganic Modified & $\begin{array}{l}\text { Acid modified } \\
\text { inorganic salt modified } \\
\text { sodium modified } \\
\text { organic quaternary ammonium salt modified } \\
\text { polymer monomer modified } \\
\text { coupling agent modified } \\
\text { organic acid modified }\end{array}$ \\
Organic Modified & $\begin{array}{l}\text { first inorganic modification } \\
\text { and then modified }\end{array}$ \\
\hline
\end{tabular}

\subsection{Inorganic Modification}

Inorganic modification is the use of inorganic additives in the cationic replacement of montmorillonite layer between the original metal cations, change the interlayer structure, thereby enhancing the adsorption of montmorillonite, surface acidity concentration and strength [5]. Commonly used inorganic modification of acid modified, inorganic salt modification and sodium modification of three. Where in the acid modification is mainly carried out by washing the montmorillonite with an acid reagent or heating the montmorillonite solution containing the acid so that the cations such as $\mathrm{Na}^{+}, \mathrm{Ca}^{2+}$ and $\mathrm{K}^{+}$in the montmorillonite layer are replaced with the soluble salts of the corresponding acid, weakened the interlayer binding force, so that the interlayer spacing increased to improve the adsorption and catalytic properties of montmorillonite; acid modified montmorillonite, can be used as bleaching agent, adsorbent and so on. The modification of the inorganic salt is the ion exchange between the cation of the montmorillonite and the cation of the inorganic metal salt, so that the montmorillonite monocrystalline monolayer is formed into lamellar association structure to achieve the modification effect, so as to improve the adsorption capacity of montmorillonite and ion exchange capacity. For the montmorillonite modified salts are mainly aluminum, zinc, magnesium, copper, etc; Natural montmorillonite to calcium-based montmorillonite, there are a small amount of sodium-based montmorillonite, aluminum montmorillonite and so on. However, the product of sodium montmorillonite is best. Commonly used sodium modification agents are sodium carbonate, sodium fluoride, sodium hydroxide, sodium polyphosphate and so on. Sodium montmorillonite has a high cation exchange, swelling, glial and high thermal dry strength and wet compressive strength [6].

\subsection{Organic Modification}

Organic modified montmorillonite is the exchange of hydrated inorganic metal cations between montmorillonite layers, increasing the interlayer spacing. Common organic modification methods are organic quaternary ammonium salt modification, polymer monomer modification, coupling agent modification, organic acid modification [7]. Organic quaternary ammonium salt modification means that the quaternary ammonium salt organic cation enters the montmorillonite layer through ion exchange, increases the interlayer spacing and reduces the hydrophilicity of the surface, improves the lipophilicity, strengthen the binding force of montmorillonite and polymer; Polymer monomer modification is the use of polymer monomer as a modifier intercalation to the montmorillonite layer, and then through the polymerization reaction of its nanocomposites, the process cost is low, high efficiency. The most commonly used polymer monomer modifier is aniline, aniline monomer into the montmorillonite layer, can be polyaniline single chain. The organic montmorillonite prepared by this method has high electrical conductivity and thermal stability; The modification of the coupling agent is the adsorption of the surface of the montmorillonite and the active functional group, and the surface modification of the montmorillonite can improve the Its wettability and compatibility. Usually with silane, titanate, stearic acid, organic silicon and other coupling agent; Organic acid modification is due to organic acid ions with good thermal stability, can be modified with its Mongolian Preparation of nanocomposites from desorite and polymer.

\subsection{Inorganic/Organic Compound Modification}

Inorganic/organic compound modification is the inorganic and organic two kinds of modified method of rational combination of use, that is, the first montmorillonite inorganic modification, in the second organic modification treatment, resulting in inorganic/organic compound type Mongolian Soil release. This method is widely used in sewage, wastewater treatment.

\section{Organic Modified Montmorillonite}

Organic modified montmorillonite is prepared by using different modifiers, treatment conditions, etc., using intercalation or ion exchange method, prepared with a special structure and performance of non-metallic mineral processing products. In recent years, with the improvement of organic modified montmorillonite, domestic and foreign researchers have carried out a lot of research.

LiLi [8] and so on with sodium montmorillonite and cetyltrimethylammonium bromide (CTAB) organic modified montmorillonite as adsorbent to the aqueous solution of dibutyl phthalate (DBP) was static the adsorption mechanism of DBP on the two adsorbents before and after organic modification of montmorillonite was studied. The adsorption mechanism of DBP on the adsorption of montmorillonite was studied. The results show that the adsorption effect of montmorillonite after organic modification is better, the main mechanism of adsorption is surface adsorption, organic modified montmorillonite is also distributed and adsorbed.

Yang Weikun [9] and so on to Henan Xinyang bentonite as raw material, after purification by sodium hexadecyl trimethyl ammonium bromide (CTMAB) as organic intercalation agent and montmorillonite layer of cation exchange, prepared layer The organic montmorillonite was characterized by XRD, TG and DSC. The adsorption conditions of organic modified montmorillonite were investigated. The results showed that when the ratio of CTMAB to montmorillonite was about 100 $\mathrm{mmol} / 100 \mathrm{~g}$ and the reaction temperature was $75^{\circ} \mathrm{C}$ for $2 \sim 3 \mathrm{~h}$, 
the interlayer spacing of organic montmorillonite was larger and the adsorption capacity of organic matter was stronger, Can be used in aqueous solution of phenolic harmful substances in the removal.

Qishan [10] and so on in order to improve the comprehensive properties of zinc-rich anticorrosive coatings, montmorillonite modified by $\mathrm{HOOC}\left(\mathrm{CH}_{2}\right)_{17} \mathrm{NH}_{3}{ }^{+}$was added to the main raw materials such as silica gel emulsion, silica sol and potassium hydroxide. $\left(\mathrm{CH}_{2}\right)_{17} \mathrm{NH}_{3}{ }^{+}$organic modified montmorillonite as anti-settling agent to prepare modified potassium silicate zinc-rich anti-corrosion coating. The results show that the addition performance of the organic montmorillonite containing the $-\mathrm{COOH}$ as the anti-settling agent is better than that of the organic smectite containing the organic montmorillonite as the antistatic agent with the end group, and the comprehensive performance of the latter is excellent In addition to the addition of anti-settling agent zinc-rich anti-corrosion coating.

Nevin Oztekin [11] studied the adsorption effect of cationic polymer polyethyleneimine (PEI) and bentonite. It was found that the adsorption between the two is due to the electrostatic interaction between bentonite particles and polyethyleneimine, Polyethylene imine cations change the rheological properties of bentonite suspensions. The adsorption capacity of bentonite to polymers and the rheological properties of polymers to bentonite vary with the exchangeable cations $\left(\mathrm{Na}^{+}, \mathrm{Ca}^{2+}\right)$ in bentonite.

Sanchez-Martin [12] and other long-chain surfactants octadecyl trimethyl ammonium bromide modified montmorillonite, kaolinite and sepiolite and other natural clay minerals, and the preparation of modified clay minerals The results showed that the adsorption capacity of modified clay minerals to organic pesticides was significantly higher than that of natural clay minerals, and the adsorption capacity of modified montmorillonite on vermicillin and metalaxyl was higher than that of natural clay minerals. Degenerate more than 100 times.

Chiu [13] and so on using dimethyl dihydrogenated tallow ammonium salt on montmorillonite modified, and polybutylene succinate copolymer adipic acid (PBSA) melt mixing, prepared PBSA-based nanocomposites material. The results showed that the organic montmorillonite was dispersed in the nanometer scale in the material, which increases the isothermal crystallization rate of PBSA, promotes the formation of nuclei and retains the crystal form of PBSA. When the amount of organic montmorillonite is $5 \%$, the material thermal stability, water absorption and elasticity were significantly enhanced.

According to a large number of experiments show that organic modified montmorillonite by ion exchange reaction, the montmorillonite layer of metal ions replaced, to expand the distance between the montmorillonite layer to increase the compatibility and adsorption of polymer compounds, so that Its adsorption performance has been greatly improved.

\section{Conclusion}

Through the above discussion, in many inorganic nano-particles, montmorillonite because of its rich mineral resources, excellent performance and low prices, which has been favored by the people. Montmorillonite is widely used in industry, from the beginning of the cationic surfactant on the surface of the clay organic treatment, to the polymer additives, toxic substances adsorbents, catalysts and so on. Especially the polymer/montmorillonite nanocomposites, so that the use of organic montmorillonite has been fully reflected. It greatly improves the mechanical properties of nanocomposites, flame retardant properties and thermal stability and other special properties [14]. Although the people on the montmorillonite modification and its application research has become more mature, but montmorillonite as a "universal material" is still a lot of research space, For example: to improve the performance of organic montmorillonite research, such as improving its high temperature stability; the organic montmorillonite synthesis process research, such as montmorillonite in the composite material to achieve complete stripping; organic montmorillonite in the application of environmental protection research, such as better play the adsorption properties of organic montmorillonite; the use of organic montmorillonite for the development of new materials and so on.

\section{References}

[1] $\mathrm{Xu}$ Weibing, He Pingsheng. Preparation and Properties of Polypropylene/Montmorillonite Nanocomposites [J]. China Plastics, 2000, 14 (11): 27-31.

[2] Wang Jincheng, Yang Ke, Zheng Xiaoyu. Organic modification of montmorillonite and its structure and properties [J]. Chemical Minerals and Processing, 2010 (7): 11-13,26.

[3] Li Na, Ma Jianzhong, Bao Yan. Research progress of montmorillonite modification [J]. Chinese Journal of Chemical Research, 2009, 20 (1): 98- 103.

[4] Xiang Ying, Liu Quanxiao etc. Montmorillonite modification method and application status [J]. Journal of Beijing Institute of Graphic Communication, 2007, 15 (4): 30-33.

[5] Yu Zhigang, Jia Zhaixia. Research progress of montmorillonite modification [J]. Progress of Fine Petrochemicals, 2005, 6(8): 5-8.

[6] Zhao Baolin, Naping, Liu Jianfeng. Research progress of modified montmorillonite $[\mathrm{J}]$. Chemical Industry and Engineering, 2006, 23 (5): 453-457.

[7] Zhou Zhiguo, Wan Liqiang etc. Polypropylene/montmorillonite nanocomposites research progress [J]. Chemical Journal, 2003, 17 (2): 1-5.

[8] Li Li etc. Effects of organic modification of montmorillonite on the adsorption of dibutyl phthalate $[\mathrm{J}]$. Industrial Water Treatment, 2015, 35 (5): 75-78.

[9] YangXing-kun,Shen Jiu-ming. Progress in Polymer/Montmorillonite Nanocomposites [J] Journal of Xinyang Normal University (Natural Science Edition), 2006, 19 (3): 268- 272. 
[10] Qishan etc. Effects of organic montmorillonite on the performance of modified potassium silicate zinc-rich anticorrosive coatings [J]. Sos silicate Bulletin, 2014, 8 (33): 89-94.

[11] Nevin Oztekin. Adsorption of polyethyleneimine from aqueous so-lutionson bentonite clays [J]. Materials Letters, 2002, 55: 73- 76.

[12] Zhang Chenyu etc. Modified montmorillonite repair of herbicides to pollute the environment [J]. Guangzhou Chemical Industry, 2015, 24 (43): 19-21.
[13] Chiu F C. Fabrication and characterization of biodegradable poly nanocomposites with halloysite nanotube and organo-montmorillonite as nanofillers [J]. Polymer Testing, 2016, 54:1-11.

[14] Feng Guangchen, Guo Yanting et al. Advances in organic modification of montmorillonite [J]. New Materials for Chemical Engineering, 2017, 45 (03): 37-39. 